\title{
A questão da metáfora, da referência e do sentido em pesquisas qualitativas: o aporte da sociopoética
}

\section{Jacques Zanidê Gauthier}

Lycée de Muret, Académie de Toulouse

\section{A posição do pesquisador em relação aos sujeitos da pesquisa}

A pesquisa qualitativa, na área de educação como em outras ciências do ser humano e da sociedade, possui um status cognitivo especial. O problema que desenvolvo aqui é o da relação entre o pesquisador e as pessoas sujeitos da pesquisa, em termos de produção de conhecimentos: Que tipo de conhecimentos cada um(a) produz, e qual o status da operação cognitiva específica, realizada pelo pesquisador a partir dos dados da pesquisa?

Essa questão é filosoficamente difícil, pois os dados de pesquisas qualitativas não são dados objetivos, positivos, brutos, e sim narrativas (histórias de vida...), entrevistas coletivas e individuais, produções artísticas, ou seja, produções de sentido. Os dados já são interpretações do mundo, dependentes de quadros conceituais culturalmente marcados, em que posições políticas estão em jogo, lutas simbólicas, fraturas e redes de alianças, que permitem a negociação e constituição do sentido. Autores como Bakhtin (1992), Bourdieu (1982) ou McLaren (1997) nos de- ram instrumentos teóricos para termos uma visão crítica e lúcida sobre as lutas na constituição do sentido das práticas sociais e na enunciação de palavras que revelem ou dissimulem esse sentido. Do seu lado, a etnometodologia e o interacionismo simbólico favorecem a compreensão das alianças e do implícito a partir dos quais os grupos se constituem como tais, ao produzirem identidades relativamente estáveis, negociadas e instituídas (Garfinkel, 1967). A corrente chamada de pós-colonial, com autores como Bhabha (1998), realiza uma forma de síntese entre a tradição centrada sobre o conflito, marcada pelo marxismo, e os aportes da microssociologia, referida a orientações fenomenológicas; assim podemos dizer que, no início do século XXI, o sujeito das enunciações, o eu falante, encontra-se cada vez mais no centro da problemática da constituição do sentido: ninguém pode falar no lugar dele, e só ele é dono de suas identidades - que foram descobertas como plurais, conflituosas e até provisórias -, assim como do sentido das suas palavras. O sujeito falante não é mais o rei cartesiano, uma consciência soberana. A crítica feita pelas filosofias da desconfiança (Nietzsche, Marx, Freud) 
é, neste ponto de vista, decisiva: a consciência de si traz muitas ilusões, ou seja, erros dos quais gostamos e, até, que participam do sentido que damos à nossa experiência e prática social. Mas os pensadores oriundos de povos que sofreram a colonização insistem em dizer que interpretar no lugar do outro o sentido de sua fala, como faz, às vezes, o pesquisador em relação aos sujeitos de sua pesquisa, é alienar esse outro, tirando-lhe sua própria humanidade de sujeito falante.

Deste ponto de vista, a abordagem proposta por Barbier (1993), baseando-se na noção de escuta sensível e em uma certa forma de consciência noética, permite instrumentalizar a pesquisa de campo em direção a um respeito da pluralidade, do íntimo e até do segredo. Eticamente, não se deve esquecer que pesquisar o outro é um ato de violência simbólica para com ele. Serres (1997, p. 15) formulou isso com vigor:

Observaram que a curiosidade exerce-se constantemente sobre os mortos e sobre os fracos sem defesa e nunca a propósito dos poderosos? Os sujeitos das ciências humanas diferem dos seus objetos, não são os mesmos homens. Já encontraram na estrada para Paris uma organização de camponeses indo para a capital para elucidar os usos dos seus administradores? Ou, voando para os Estados Unidos, encontraram no avião uma escola de Zulus ou de Guaranis, indo para realizar um seminário sobre alguns sábios em destaque da América? Outrora, os dominantes colonizavam os dominados, agora eles nos observam.

Queria que se inscrevesse nas constituições o direito dos homens e dos povos de recusarem ser estudados. (tradução minha)

Realizar uma pesquisa é assumir um status de poder sobre os sujeitos da pesquisa, a partir de um lugar cognitivo específico. Da mesma maneira que esses sujeitos produzem o sentido de suas palavras em complexos processos de lucidez e cegueira, luta e negociação, identificação e desidentificação, o pesquisador produz o sentido (em processos semelhantes de lucidez e cegueira, luta e negociação, identifi- cação e desidentificação) de sua própria fala em direção aos pesquisados e, sobretudo, ele produz o sentido da escrita final de sua pesquisa, cuja existência não teria sido possível sem a participação e colaboração dos sujeitos da pesquisa (dissertação, tese, relatório de pós-doutorado...).

Os pesquisadores da nossa área, tendo conhecimento dos teóricos que fazem essas considerações, podem assumir uma posição de vigilância epistemológica, pois são teoricamente armados para irem ao campo de pesquisa. Eles possuem um olhar crítico $a$ priori sobre a cegueira específica gerada pela sua posição de poder no saber (Foucault, 1976) e são teoricamente capazes de analisar sua implicação no seu objeto de pesquisa, ou seja, seu inconsciente institucional (Lourau, 1970; 1988): o que está em jogo e pertence de maneira escondida ao processo de pesquisa, à busca, à constituição do objeto de estudo e dos métodos de investigação no campo simbólico e ideológico, no campo pulsional, no campo material e organizacional?

A dificuldade começa quando se trata de ir além da proclamação da exigência ética de respeitar os desejos e direitos dos sujeitos da pesquisa e de construir um distanciamento crítico para com sua própria posição institucional. Quando, no decorrer mesmo da pesquisa, interferem esses processos complexos de produção de sentidos, a partir de posições de poder dissimétricas. Para pensarmos melhor o campo semântico assim criado, proponho retomar a questão do sentido e da referência. Mas não se tratará de repetir as discussões clássicas de Bertrand Russell (1961) e Frege (1952) no campo da lógica, independentemente dos aportes das recentes teorias lingüísticas da enunciação. Encontramos na obra de Deleuze e Guattari (1980) uma conceitualização, desses aportes, diretamente utilizável pelos pesquisadores de campo.

\section{Agenciamentos maquínicos e enunciativos}

Segundo Deleuze e Guattari (1980, p. 112), existe um duplo agenciamento, de conteúdo e de expressão que chamamos duplagem: 
O agenciamento maquínico de corpos, ações e paixões, mistura de corpos agindo uns sobre os outros.

$\mathrm{O}$ agenciamento coletivo de enunciação, de atos e enunciados, transformações incorporais atribuindo-se aos corpos (grifos do original).

Os autores continuam precisando:

[...] o agenciamento tem, de um lado, lados territoriais ou reterritorializados, que o estabilizam, e de outro lado, pontas de desterritorialização, que o levam embora (idem).

\section{O que é um agenciamento maquínico de corpos, ações e paixões?}

Corpos atraem-se, repulsam-se, alteram-se, fazem alianças, combinam-se em aliagens, expandemse, penetram-se, excluem-se. Esses corpos podem ser corpos ou partes ou grupos de corpos humanos, e seres naturais, ferramentas, máquinas, energias, que se compõem ou transformam segundo regras, em tempos e lugares instituídos. Assim, a vida familiar numa classe dada da sociedade é um agenciamento maquínico, outro é a vida numa faculdade, ainda outro uma organização comunitária. O importante é que existem nessa máquina física poços de captura, que atraem as energias em pontos instituídos, repetitivos, reprodutores dele, devoradores; e existem, inversamente, linhas de fugas desejantes, criadoras de jogos não previstos, que nem sempre vêm por vontade própria das pessoas, mas perpassam o conjunto de corpos e afetos. Uma forma de desordem criadora, de caos na organização.

\section{O que é um agenciamento coletivo de enunciação?}

Ele é composto das múltiplas falas e discursos possíveis que produzem a subjetividade - essa não é individual, e sim coletiva, conectando signos diversos. As enunciações não representam os conteúdos (os corpos e afetos), pois possuem forma e coerência próprias. Elas podem antecipar, atrasar, tirar, cortar, juntar diferentemente... esses conteúdos. Retomemos os exemplos da cultura familiar, ou universitária, ou comunitária. Vê-se facilmente a importância desse agenciamento complexo de enunciados na constituição mesmo da subjetividade, assim como daquilo que é chamado de cultura. Existem poços, rios, trilhas, avenidas, terras, ventos, fronteiras, fluxos, toda uma geografia onde as palavras se juntam, comem, pegam, apagam, superpõem, parasitam, traem, espalham, escondem. Aqui também, o relevante é a existência de pontos de territorialização, que atraem vários discursos no mesmo campo semântico, fazem ecoar uns em outros, conectando-os, ou então supercodificando, numa forma geral dominante, conteúdos diversos. É por um processo de supercodificação que se produz o que Gramsci (1977) chamava de cultura hegemônica. Mas existem também pontos de desterritorialização, expressões de desejo instituintes, palavras que não podem ser capturadas pela ordem instituída. O que a linguagem política chama de culturas de resistência são conjuntos de linhas que convergem em direção a um território, ou até criam um território novo, cuja ordem semiótica é heterogênea em relação à ordem instituída, e não é capturada. Como na filosofia de Michel Foucault, as relações de poder e desejo estruturam o campo de enunciação (Deleuze \& Guattari, 1980, p. 101): "Não há significância que seja independente dos significados dominantes, não há subjetivação que seja independente da ordem estabelecida de sujeição".

Bacias de captura ${ }^{1}$ interligadas geram o que é chamado de cultura dominante ou hegemônica, enquanto agenciamentos discursivos heterogêneos, parcialmente capturados por esses significados dominantes, produzem o que é chamado de cultura dominada. Por exemplo, a canção popular, quando submissa aos

\footnotetext{
${ }^{1}$ Em francês, bassins de capture é um conceito oriundo da
} teoria das catástrofes, atribuída ao matemático René Thom. Pode ser traduzido também como atratores, em referência à física do caos. 
padrões estéticos e econômicos do showbiz, ou ainda as formas de expressão dos afro-descendentes, quando tornadas invisíveis ou folclorizadas em padrões utilizados pelas classes dominantes.

Uma forma de resistência interna a um agenciamento é a variação, que dificulta qualquer forma de codificação prévia. Multiplicar as variações, deshomogeneizar, é criar a autonomia, resistir à média onde mora a maioria. Criar ligações inesperadas é uma outra forma de resistência. É a desterritorialização, a emergência de desejos instituintes.

\section{Os componentes dos agenciamentos coletivos de enunciação}

Os agenciamentos coletivos de enunciação podem viver segundo quatro componentes de signos diferentes (Deleuze \& Guattari, 1980, p. 181-182), que a pragmática ou esquizo-análise, ou ainda rizomática, estuda. Conscientizar-se desses componentes é de fundamental importância na análise dos dados, ou seja, na análise do agenciamento coletivo de enunciação produzido pelos participantes da pesquisa. Encontramos:

- O componente generativo, que mostra como toda expressão combina vários regimes de signos. Isso significa, por exemplo, que não existe uma cultura pura, que não se pode adjetivar de maneira unívoca a cultura. Por exemplo, expressões como cultura popular, cultura indígena ou cultura burguesa não possuem nenhum sentido unívoco, sendo geradas por combinações de desejos (Deleuze \& Guattari, 1980) e por articulações de poder (Foucault, 1976). Não é necessário uma coerência a priori entre os elementos interligados para que se criem constantes, comportamentos previsíveis, habitus. A coerência pode ser criada après-coup, por um processo de supercodificação, de ecos que se reforçam mutuamente. Para o pesquisador, o difícil é desconfiar da armadilha da coerência e da coesão entre os discursos, pois muitas ve- zes essa coerência só tem por função simplificar e homogeneizar o que é heterogêneo. O erro é acreditar na unicidade orgânica das formas de vida discursiva e incorporar essa simplicidade. Diante disso, a pesquisa resgata a polissemia dos signos. Não se deve temer a ambigüidade, a ambivalência e o paradoxo, que sempre são índices de um problema interessante.

- O segundo componente é, na teoria de Deleuze e Guattari (1980), o componente transformacional, que mostra como um regime pode ser traduzido num outro, e um novo ser criado a partir de transformações. Um exemplo conhecido é o nascimento do candomblé no Brasil, por interferência entre formas de vida coletiva e espiritual características de vários povos africanos deportados pela escravidão. Uma questão vai ser de se entender como tal criação transformacional pode agir em outras áreas da realidade, até que ponto ela pode ser traduzida na esfera do trabalho, da vida do bairro, da educação etc. É muito provável que, num país que se fez pela imigração e miscigenação, forçadas ou voluntárias, os processos discursivos de tradução e transformação estejam muito ativos nos posicionamentos dos sujeitos falantes nas nossas pesquisas.

- O terceiro componente enunciativo é o componente diagramático, em que é visível como signos são extraídos de formas originárias, aparecendo como partículas desterritorializadas, capazes de serem combinadas entre elas. $\mathrm{O}$ samba carioca nasceu provavelmente dessa forma, a partir de tradições musicais do povo negro (samba de roda de ritmo Cabula), em interação com a classe média branca, com um complexo sistema de irrupção de marcadores rítmicos e corporais negros, e de tentativas de controle social da parte das classes dominantes. A MPB é rica de criações do que Deleuze e Guattari (1980, p. 183) chamam de "[...] dialeto do gozo, de físicas e semióticas em peda- 
ços, de afetos não subjetivos, de signos que nada significam, onde caem a sintaxe, a semântica e a lógica". Podem ser o pior ou o melhor, o xarope e a vulgaridade de algumas produções comerciais, mas também a desarticulação do corpo e o nascimento de sopros nunca ouvidos. Encontramos aqui os marcadores da semiótica corporal infra-lingüística, ${ }^{2}$ que vários autores (Bakhtin, 1970; Kristeva, 1969) valorizaram muito pelo entendimento do sentido político do que é dito e sugerido. Com efeito, o corpo é o lugar em que os valores podem ser invertidos (no pensamento carnavalesco de Rabelais, segundo Bakhtin) e em que as entonações, os gritos e sussurros expressam o que escapa da ordem semântica: da intencionalidade racional, das classificações políticas impostas entre o que pode ser dito e como, e o que não pode ser expresso. Nossas pesquisas não podem perder essa dimensão, particularmente explícita nas classes populares, da constituição do sentido das práticas sociais pelos sujeitos das pesquisas educacionais.

- O quarto componente é o componente maquínico, em que os dois agenciamentos, as duplagens, interferem uma na outra. As expressões modificam os corpos e as paixões, enquanto esses geram formas de expressão novas. Alguns chamam isso de práxis, outros de clínica. Em pesquisas cujo método consiste em transformar para conhecer, ou seja, introduzir uma perturbação no meio para estudar as suas rea-

${ }^{2}$ Aqui encontramos um problema de definições: Benveniste (1966) chama de semântica a constituição do sentido ao nível lógico da frase, por oposição à semiótica, concebida ao nível do signo. Isso permite a problematização da intencionalidade e do implícito e abre caminhos para as futuras análises de discurso. Já Kristeva (1969) chama de semiótica a constituição do sentido a partir das pulsões, da ordem e desordem do corpo, cuja linguagem pré-semântica participa da elaboração inconsciente do sentido político da práxis. ções, esse componente está particularmente presente.

Essa caracterização dos componentes enunciativos por Deleuze e Guattari é muito interessante, por ser fácil de usar na análise dos dados em nossas pesquisas. Além disso, ela realiza uma boa síntese dos conhecimentos trazidos pela lingüística do discurso e da enunciação. É só seguirmos esse quadro de pensamento e ganharemos muito em termos de precisão nas análises enunciativas dos dados.

\section{A questão da metáfora, do sentido e da referência}

Para facilitar tal procedimento, é desejável tomar como foco prioritário de estudo as metáforas utilizadas pelos sujeitos da pesquisa. Por que as metáforas?

Porque elas possuem um status ambíguo na linguagem, que tornam fáceis de serem vistas as ligações entre agenciamentos, as desterritorializações dos significados, as traduções de um regime de signo para um outro e a combinação desses regimes, ou seja, os quatro componentes enunciativos acima mencionados.

Com efeito, além de definirem a metáfora como uma comparação implícita entre termos oriundos de registros heterogêneos, muitos lingüistas (Ricoeur, 1975) consideram-na como uma regra constitutiva da língua que indica como se pode encontrar ou criar um objeto diferente e semelhante, e, ao mesmo tempo, apresentar intuitivamente o ícone desse objeto. Portanto, a metáfora está entre o mundo do sentido (interno à linguagem) e o mundo da referência (da realidade não-lingüística). Ela é o índice de um trabalho do espírito, que elabora um conflito, uma tensão dentro da língua (entre o que a metáfora é, por ser semelhante, e o que ela não é, por ser diferente), e entre a língua e o real (pois a metáfora visa a algo que não está dado, que não está presente, ela dá vida a um produto da imaginação).

Em minhas pesquisas, essa característica de se dar entre os significados e entre a língua e o mundo, 
faz da metáfora um potente instrumento de identificação do sentido que os sujeitos projetam no mundo. Nossa escuta sensível pode tranqüilamente ser focalizada nas metáforas das gravações oriundas de minhas pesquisas de campo; tenho certeza de encontrar aí um tesouro de dados interessantes. Com efeito, metáforas usadas, quando escolhidas pelos sujeitos das pesquisas, apontam para uma certa dependência para com as ideologias instituídas, para um certo fechamento numa territorialização prévia, enquanto a criação de metáforas vivas, como diz Ricoeur, quebra as categorizações congeladas da língua e do mundo, resgatando o poder classificador originário da linguagem e criando um esboço de significações (discursivas) e percepções (intuitivas) novas. Paul Ricoeur (1975, p. 263) fala, até, de "desmancho das áreas semânticas sob o choque das contradições".

Hester (1967) relaciona diretamente essa característica das metáforas ao poder de metaforização, que é um dos princípios geradores da linguagem. Uma metáfora tomada a sério obriga o ouvinte a suspender sua relação instituída com o real, já constituída de muitas metáforas mortas, esquecidas, que caíram fora do campo da consciência, e a abrir-se para o virtual: ver-como é deixar acontecer o evento do fluxo das imagens, deixar-se trabalhar pela imaginação criadora, sem perder de vista que esse fluxo não acontece sem regra nem ordem, e sim é um produto de condições sócio-históricas (coletivas e individuais) que trabalham a linguagem coletiva, assim como nossa fala privativa.

Entre pensamento e experiência, entre o coletivo e o singular, a metáfora é, como escreve Ricoeur (1975, p. 271), "a solução de um enigma", ou seja, o paradoxo da passagem intuitiva para o não-verbal (ver a imagem), através um tropismo da língua.

Em termos de pesquisa qualitativa, encontramos aqui essa tensão muito produtiva, para nós pesquisadores da área educacional, entre os conhecimentos prévios dos sujeitos da pesquisa e o que eles sabem não saber, ou melhor, querem e imaginam, mas sabem ainda não saber. Será que aí se vai constituindo uma vygotskiana zona de desenvolvimento proxi- $m a l,{ }^{3}$ no próprio processo de pesquisa, entre os sujeitos da pesquisa e o pesquisador?

Além dessa importância cognitiva, Bachelard (1957, p. 7) expressa a importância ontológica da imagem poética:

[...] ela torna-se um ser novo da nossa linguagem, ela nos expressa ao fazer de nós o que ela está expressando, ou seja, ela é, ao mesmo tempo, um devir de expressão e um devir de nosso ser. Aqui, a expressão cria algo do ser.

Para nós, pesquisadores, é de fundamental importância o sétimo estudo, "Metáfora e referência", da obra citada de Ricoeur (1975), A metáfora viva. O sentido das falas ditas e/ou escritas, numa pesquisa qualitativa, seja pelo pesquisador acadêmico, seja pelos sujeitos da pesquisa, está totalmente dentro do que é dito. Geralmente, os lógicos concordam com Russell e Wittgenstein que, contra as visões positivistas e científicas comuns (armadilha na qual o desencantamento do mundo nos faz cair), chamam os fatos de existência de estados de coisas, expressando assim que os fatos são, na verdade, atos predicativos da mente humana. $O$ fato não é a referência, aquilo que existe em si. A referência denotada pela descrição (há...) pode somente ser aquilo que é visado pelo mundo do sentido, pelo discurso. Agora, o que podemos dizer sobre o que somente está aqui, ou não está? A referência, chamada por Frege de denotação, abre para o além do dito, ou seja, para aquilo sobre o qual é dito o sentido. Isto é, nas nossas pesquisas, para o mundo social visado. Conhecemos esse mundo referencial em negativo: ao falarem, os sujeitos da pesquisa torcem o sentido das

\footnotetext{
${ }^{3}$ Vygotski (1985) criou o conceito de zona de desenvolvi-
} mento proximal a partir da relação dialética entre o nível de desenvolvimento potencial e o nível de desenvolvimento real. Essa zona borda a trajetória que o sujeito percorre para desenvolver níveis de amadurecimento das estruturas simples a partir de estruturas complexas que ele ainda não conquistou de forma independente, mas que, com a ajuda do outro, ele consegue atualizar. 
palavras comuns, segundo a singularidade de cada situação, visão, projeto. É essa singularidade que devemos apontar, para podermos, em seguida, interrogá-la em relação à sua contribuição para efeitos enunciativos reprodutores das metáforas instituídas ou criadores de metáforas novas, vivas, entrando em composições, traduções, diagramas ou máquinas enunciativas que a teoria proposta por Deleuze e Guattari permitem identificar.

É esse processo de torção, no qual algo é dito do real ao mesmo tempo que dito de outro jeito, estranhando o familiar, ou seja, visando uma realidade outra, virtual, que está presente na metáfora viva como emergência de um sentido ainda desconhecido. Chamamos de sociopoética nosso método de pesquisa método no sentido de Morin (1986), ou seja, caminho que se faz caminhando, mais aberto para o imprevisto do que seria uma metodologia - precisamente porque estamos atentos à experiência radical que a poesia propõe: em lugar de descrever o que é dado, como faz o uso comum, positivista e utilitarista, da linguagem, ela afasta do julgamento comum e pretende ir até o limite da potência de criar o mundo, presente na linguagem (Coletivo de autores, 1999; Gauthier, 1999a).

O poema como agenciamento discursivo é uma unidade metafórica: como a metáfora, mas num sentido mais amplo, ele transfere o que era pertinente em certos agenciamentos de corpos no mundo das coisas sem interesse e dá a maior pertinência ao que era impertinente. Cabe aos leitores fazerem uma parte do caminho.

Como um poema o realiza de maneira radical, a metáfora traz tensões num mundo que se apresentava como pacífico, desproblematizado. É isso que é apaixonante para os pesquisadores que buscam uma reproblematização do mundo. E quem vai reproblematizar esse mundo, a não ser os próprios sujeitos da pesquisa, no quadro de um dispositivo que facilite essa operação cognitiva?

Além disso, a metáfora cria suas referências num modo virtual, o que permite à lingüista Hesse (1965) falar de ficções heurísticas e afirmar que a racionali- dade se constitui, nas próprias ciências, pela expansão de metáforas, de onde surgem os principais modelos cognitivos utilizados pelos físicos. Como os modelos científicos, os mitos funcionariam segundo esse mesmo princípio de expansão metafórica, apresentando coisas humanas na forma de aventuras divinas sistematizadas.

Daí o aspecto social contido na palavra sociopoética. A poética presente na criação verbal dos participantes da pesquisa funciona de modo coletivo, marcado cultural e socialmente, e também de modo cooperativo: na produção coletiva de um mundo metafórico, ou melhor, na interferência de metáforas referidas a mundos semânticos heterogêneos, o grupo das pessoas sujeitos da pesquisa elabora ficções, desenha modelos de uma realidade sem dúvida complexa e imaginária, mas racional. $\mathrm{O}$ dispositivo de pesquisa deve, nesse momento, ser suficientemente potente para catalisar a expansão poética desse processo de metaforização e, em seguida, favorecer sua análise crítica pelos próprios sujeitos da pesquisa.

O interessante é que a ficção heurística vem da impertinência semântica contida na metáfora. Da qualidade de suas tensões internas e da pertinência de sua impertinência (de seu deslocamento problematizador das referências) depende a justeza da metáfora, ou, para falar como Foucault (1976), seus efeitos de verdade.

\section{Impertinência semântica e abdução}

Como processo cognitivo, a metáfora é um raio que gera uma nova categoria de conhecimento envolvendo dois campos de saber, alterando nossa compreensão de um como do outro e, sobretudo, realizando um deslocamento no pensamento, uma fuga criadora em direção a terras novas. Ela favorece processos intelectuais intuitivos. Isso é particularmente relevante nos estudos culturais, quando interferem campos de saber e aprendizagem heterogêneos.

Lembremos as quatro formas de abdução, forma lógica que a língua comum chama de intuição, se- 
gundo Peirce ${ }^{4}$ (Eco, 1991, p. 228-229): hipercodificada, ela acontece quando interpretamos o significado de uma palavra a partir de uma reconstrução do contexto; hipocodificada, quando escolhemos uma hipótese entre várias, baseados na crença da regularidade do mundo; criativa, quando reinventamos uma lei deste mundo, por exemplo, ao intuirmos relações inesperadas entre áreas heterogêneas; a quarta forma é a meta-abdução, quando decidimos que o universo que imaginamos no nosso pensamento corresponde ao universo da nossa experiência cotidiana. Para Umberto Eco, esta última forma caracteriza a criação científica e a investigação policial.

Encontramos, diretamente, na terceira e na quarta forma de abdução, a ação da metáfora na construção do conhecimento.

Particularmente, é provável que nas nossas pesquisas interculturais encontremos freqüentemente, nas metáforas utilizadas pelos sujeitos das pesquisas, abduções potenciais, que só precisamos desenvolver, em parceria com o grupo-pesquisador. Sebeok e Umiker-Sebeok (1991, p. 23) afirmam que a abdução gera um tipo de emoção que a coloca à parte da dedução e da indução. O desafio cognitivo toma a forma de uma emoção na nossa relação com o que chamamos de mundo e na nossa crença nas formas desse mundo. Será que essa emoção é a mesma que encontramos no nosso relacionamento com os sujeitos de nossas pesquisas, que pertencem a mundos cognitivos não homogêneos com o nosso? Sem a abdução não existiria a própria vida, acrescentam Sebeok e UmikerSebeok. É um instinto que percebe as conexões inconscientes do mundo, é a comunicação subliminar de mensagens.

Eles referem-se diretamente a Peirce (1935-1966, par. 2.643). Essa citação é muito esclarecedora e merece ser reproduzida in extenso, pois dá uma sustentação teórica ao nosso método sociopoético de pesquisa:

${ }^{4}$ A questão da abdução na semiótica de Peirce é tratada sob múltiplos aspectos por vários autores. Ver Eco e Sebeok (orgs.), 1991.
A hipótese substitui uma concepção simples por um complexo emaranhado de predicados vinculados a um sujeito. Mas, há uma sensação peculiar pertencente ao ato de pensar que cada um desses predicados impregna no sujeito. $\mathrm{Na}$ inferência hipotética, esse sentimento complexo, assim produzido, é substituído por um sentimento simples de maior intensidade, aquele que pertence ao ato de pensar a conclusão hipotética ${ }^{5}$. Agora, quando nosso sistema nervoso é excitado de uma maneira complexa, havendo uma relação entre os elementos da excitação, o resultado é um distúrbio harmônico singular, o qual eu chamo de emoção. Deste modo, os vários sons produzidos pelos instrumentos de uma orquestra incidem sobre o ouvido e o resultado é uma emoção musical peculiar, inteiramente distinta dos próprios sons. Essa emoção é, essencialmente, o mesmo que uma inferência hipotética, e qualquer inferência hipotética implica a formação de uma tal emoção. Podemos dizer, portanto, que a hipótese produz o elemento sensual do pensamento e a indução o elemento habitual. (grifos do original)

O segredo de nossas pesquisas?

A metáfora é intimamente ligada ao processo de raciocínio abdutivo: ela cria elos entre áreas heterogêneas da realidade; através desses elos passam emoções e sensualidade. Geralmente, esses elementos estão explicitamente agindo nas pesquisas qualitativas, mas temos dificuldades em analisá-los.

É possível afirmar que para nós, pesquisadores em educação, a metáfora é a via real em direção ao implícito da vida cognitiva dos sujeitos de nossas pesquisas e à compreensão da nossa relação com esses sujeitos. Somos principalmente caçadores de metáforas, na fala e nos silêncios de nossos parceiros em pesquisas. Isso, segundo dois eixos: as metáforas tornam

${ }^{5}$ Essa noção de conclusão hipotética é de fundamental importância nas pesquisas qualitativas. Na sociopoética, os facilitadores de pesquisa podem somente concluir hipoteticamente. Eles vivem potentes emoções na sua relação com os demais membros do grupo-pesquisador. A devolução dessas hipóteses para o grupo permite, ao mesmo tempo, uma negociação dialógica dos resultados da pesquisa e o distanciamento de cada um de suas implicações emocionais e cognitivas no tema-gerador da pesquisa. 
problemático um dado da experiência social e educacional que parecia óbvio; além disso, elas favorecem a abdução, sem a qual não há descobertas científicas, como afirma Peirce. Ricoeur (1975, p. 321) fala de veemência ontológica, e podemos falar de energização do agenciamento coletivo de enunciação. Na página 291, Ricoeur sintetiza esses aspectos, ao escrever: "A excelência estética é uma excelência cognitiva".

A metáfora liga arte e ciência, pois a invenção por aproximação de estruturas heterogêneas é a base de potentes efeitos de verdade em várias áreas da prática social.

Será que sem metáforas não há pesquisa, logo, nenhuma descoberta?

É só ampliar essa visão da força metafórica da língua comum, falada por pessoas comuns, para se perguntar se, finalmente, existe uma referência última, realista, que seria como o solo do núcleo comum a todas as representações, e então responder, obviamente, que não. As metáforas ecoam umas às outras, pois nenhum sentido, nas enunciações cotidianas, existe sem ter conexões com referências múltiplas, dimensões heterogêneas da vida social (componente generativa). Nessa rede de ecos nascem metáforas vivas (componente diagramático). O saber mais abstrato possui ligações recíprocas com afetos e emoções (componente maquínico).

Assim deve a pesquisa qualitativa visar explicitamente às interferências, ou seja, às denotações copresentes (mesmo que geralmente heterogêneas) na experiência de cada um (componente transformacio$n a l$ ), enquanto essa experiência possui um sentido que a pessoa pode expressar. Isso relaciona a metáfora com as formas hipercodificada e hipocodificada da abdução segundo Peirce, pois tanto a reconstrução do contexto como a crença na regularidade do mundo acontecem em referências interligadas, na mente de cada sujeito da pesquisa.

A metáfora é o vínculo privilegiado que transporta os sentidos da vida cotidiana de um mundo semântico para um outro, participando da co-construção de agenciamentos coletivos de enunciação. É a experiência prática da vida, base da criatividade po- pular, como mostrou com força Certeau (1980). Acontece também esse tipo de construção quando desenvolvemos uma pesquisa científica. Isso nos dá a responsabilidade de estarmos atentos a todas as formas de abdução virtualmente contidas nas metáforas, ou seja, hiper e hipocodificada, criativa e metaabdutiva.

\section{A sociopoética}

Daí surge a idéia de inventar um dispositivo de pesquisa que favoreça a investigação das relações entre os sujeitos da pesquisa, das interferências ou interreferências constitutivas da intencionalidade de se dar um mundo comum e de criar, por metáforas, um mundo poético por certo heterogêneo, mas compartilhado, no próprio processo de pesquisa. O grupo-sujeito, segundo Sartre (1960), origem filosófica dos grupos donos do processo de pesquisa-ação no sentido de Barbier (1998), próximo do círculo de cultura segundo Paulo Freire (Freire, 1987), pode ser chamado de grupo-pesquisador, numa concepção da pesquisa qualitativa que focaliza a pesquisa como processo, ou seja, como ela transforma o meio onde acontece, enfatizando as perguntas seguintes: Quais os efeitos produzidos pelo processo de pesquisa entre os sujeitos?; Quais, entre seus conhecimentos plurais (seus enunciados)? Outra pergunta: Quais os efeitos produzidos entre seus conhecimentos de um lado, e seus afetos, de outro lado? $\mathrm{Ou}$ melhor, por que as coisas não são separadas assim, para quem trabalha com máquinas enunciativas: $O$ que acontece no entre-dois do saber e do sentir? Isso, no grupo inteiro, que inclui o pesquisador acadêmico chamado de facilitador da pesquisa. De fato, uma pesquisa sociopoética é uma auto-análise coletiva, facilitada por pessoas praticando dispositivos e técnicas apropriados.

\section{O grupo-pesquisador}

Para responder a esse tipo de pergunta, e também poder observar afetos e saberes no estado nascente, ou seja, emergentes, é preciso constituir um 
grupo-pesquisador, responsável pelo desenvolvimento do processo de pesquisa, pois assim interagem afetos desindividualizados e vão criando-se figuras novas e emergentes a partir dos conhecimentos presentes no grupo. Essa instituição dos sujeitos da pesquisa em grupo-pesquisador é o primeiro princípio da sociopoética.

\section{As culturas dominadas e de resistência}

O segundo princípio da sociopoética, considerando a dialética que se vai instituindo entre o pesquisador acadêmico e os demais membros do grupopesquisador chamados de co-pesquisadores, é, logicamente, o princípio da valorização das culturas dominadas e de resistência na produção e leitura dos dados. Com efeito, por razões que podem ser de recalcamento por causa de repressão e sofrimento (opressão dos corpos e das mentes) ou de culto dado ao segredo, ao silêncio e ao corpo (culturas negras e indígenas), a leitura clara do que é dito e não-dito nas metáforas, do que elas estão visando, intuindo e ignorando, não é possível pelas meras armas teóricas do racionalismo. É necessário a ajuda de fontes de leitura mais intuitivas, sensíveis e até simbólicas, para que se entenda a complexa riqueza das imagens metafóricas. Já se cria a metáfora na interseção de mundos com apalavramentos e acertos (segundo a expressão de Sodré, 1999) heterogêneos. ${ }^{6}$ É impossível deixar se perder essa riqueza intercultural que percorre o mundo semântico brasileiro: as referências

${ }^{6} \mathrm{O}$ apalavramento é uma raiz, um rizoma discursivo plantado numa terra sociocultural que liga o sujeito enunciativo a uma comunidade por uma promessa e uma fidelidade. O acerto é o processo de negociação que liga o sujeito, coletivo ou individual, a sujeitos ou comunidades de fora. Apalavramento e acerto são de fundamental importância nas comunidades afro-brasileiras e permitem definir o conceito de comunalidade como "ligado a um conjunto de redes de alianças comunitárias que instituem formas de expansão e afirmação existencial de um continuum civilizatório" (Santos, 2001, p. 37). negras e indígenas possuem essa força cognitiva ímpar de relacionarem-se diretamente com o que Julia Kristeva chama de elemento semiótico pulsional e corporal, ou seja, com o componente propriamente maquínico da duplagem entre os agenciamentos maquínicos de corpos e afetos e os agenciamentos coletivos de enunciação, o componente mais complexo e sensível a devires transformadores.

\section{Conhecer com o corpo inteiro}

O terceiro princípio da sociopoética é conhecer com o corpo inteiro: a emoção, as sensações, a intuição, a gestualidade, a imaginação... e não apenas com a razão. Ele vem de práticas sociais dominadas no mundo intelectual de hoje: de enfermeiros que mexem com os corpos doentes e aprendem, na sua prática, a conhecer com o corpo inteiro; de pesquisadores em educação popular que encontram corpos dançando, cantando, rodando, festejando apesar de marcados pelo açoite físico ou moral. De vários componentes populares da sociedade brasileira, principalmente de origem africana e indígena. Muitas vezes, a pele, os nervos, os músculos, as pernas, o útero, a ginga... sabem o que o cérebro esquerdo ainda não sabe simbolizar. Varela, Thompson e Rosch (1993) nos lembram que a forma mais relevante de conhecer, origem de outras formas mais descontextualizadas, é conhecer pela prática, resolvendo problemas vitais que mobilizam o corpo inteiro, com todas as suas faculdades de adaptação e criação (gestualidade, sentidos, categorização, imaginação, emoção, criação de conceitos, intuição...). Muitos especialistas das ciências contemporâneas concordam em afirmar que o relevante é entender e compreender como são produzidos os conhecimentos, isso influenciando o $q u e ̂$ (o conteúdo, o significado) dos conhecimentos produzidos. $^{7}$

\footnotetext{
${ }^{7}$ Essa problemática percorre a obra de Michel Serres, parti-
} cularmente os cinco volumes de Hermes (1969, 1972, 1974, 1977 e 1980). Sobre a questão do corpo, citaremos Serres (1985). 


\section{Técnicas artísticas de produção de dados}

Obviamente, é muito mais fácil estudar metáforas quando se usam técnicas de pesquisa favorecendo um processo de metaforização da experiência pelos próprios sujeitos da pesquisa. Isso constitui o quarto princípio da sociopoética. Precisamos, no mundo da pesquisa qualitativa, de várias técnicas artísticas de produção de dados. Como existe uma arte-educação, existe igualmente uma arte-pesquisa. Colocar o grupo-sujeito da pesquisa numa posição criadora permite ganhar em dois terrenos: em primeiro lugar, no levantamento dos preconceitos e elementos ideológicos instituídos que envenenam a vida intelectual (inclusive a vida dos pesquisadores acadêmicos, que aprendem dos demais membros do grupo-pesquisador a olharem suas costas, sua sombra preconceituosa, ou seja, o que ficou não-analisável antes do encontro com os parceiros de pesquisa); em segundo lugar, na observação (na presença atenta, diz o zen-budismo, segundo Varela, Thompson e Rosch, 1993) do modo de as imagens e metáforas novas, criadas na interação, emergirem aqui e agora, e dos ambíguos ou dialéticos significados que se vão tecendo e torcendo no grupo-pesquisador.

Luís Vítor Castro Júnior, Maria Geovanda Batista e Jacques Gauthier (2003) expressam isso ao apontarem a etimologia da palavra ilusão, através do latim il-ludere, que inclui o brincar. Maria Geovanda Batista foi facilitadora, com a ajuda de mulheres idosas Pataxó, de uma pesquisa sociopoética sobre os sentidos do brincar no mundo do povo indígena Pataxó. Os referidos autores escrevem:

Com o grupo-pesquisador Pataxó, a atividade rituallúdica está sendo traçada como mussaraitáua - brinquedo no pidjin caboclo, que significa etimologicamente lugarde-esquecer. Esquecer o inútil, aquilo que impede a presença imediata, a intuição. Outra construção no plano, que se contrapõe à visão do ritual como droga, ópio do povo (Marx), ilusão (da raiz latina il-ludere, brincar em) vital da força de vida (Nietzsche), já enganada pelos Portugueses procurando os habitantes das Índias ou, mais provavelmente, a terra da redenção. Ao rizomatizarmos com sua própria cultura, suas memórias e com a imaginação mito-poética, fomos evidenciando uma nova compreensão do brincar, porque todos os Índios brincam. E brincam juntos, crianças, jovens, adultos e velhos, participam dos jogos de uma maneira complementar, cooperativa e muito semelhante. Do mesmo modo, como é semelhante, a participação das crianças no trabalho coletivo, na produção artística e em tudo que diz respeito à produção deste brincar. (no prelo)

Vê-se nesse exemplo como a metáfora do brincar como lugar-de-esquecer, consolidada na língua, é como uma imagem dialética, que condensa tanto a tradição ancestral e a história como a abertura para devires inesperados e desejados, por serem o modo coletivo de se intuirem conhecimentos, até mesmo pela busca iniciática do transe.

\section{O sentido da pesquisa}

O quinto e último princípio da sociopoética diz respeito à responsabilidade do grupo-pesquisador na socialização dos resultados e na interrogação do sentido social, político, ético, espiritual da pesquisa. Nada de moralista nisso, podendo a pesquisa ser, com proveito em termos de produção de conhecimentos, correta ou perversa: isso depende dos desejos do grupo-pesquisador.

\section{A metáfora viva e o confeto em pesquisas sociopoéticas}

No quadro limitado deste artigo, quero dar somente o exemplo de uma técnica artística (no caso, poética) favorecendo a visibilidade de metáforas, mortas ou vivas, instituídas na língua ou que emergem no seio do grupo-pesquisador, ou seja, provar aos leitores que nossa discussão teórica tem efeitos práticos interessantes para nós e nossos orientandos.

Numa pesquisa apoiada pelo $\mathrm{CNPq}$, realizada com três grupos-pesquisadores de uma escola comunitária de Salvador (BA), de crianças, de educadoras e de pais e mães, colocamos, após realização de um relaxamento tendo por objetivo um menor controle 
racional sobre a fluidez das imagens que surgem, as seguintes perguntas:

Se as coisas mais importantes que você aprendeu, na vida, na escola, na família, na rua, fossem uma Terra, como seria essa terra? Após vinte segundos: Se fosse um Túnel, como seria esse túnel?... Se fosse um Caminho?... Um La-

birinto?... Um Arco-íris?... Uma Ponte?... Uma Gruta?... Uma Galáxia? (Gauthier, 1999b)

As crianças desenham e, numa outra sessão de pesquisa, comentam seus desenhos em relação ao conceito de aprendizagem. Essa técnica é chamada de técnica dos lugares geomíticos. O objetivo da pesquisa era comparar as aprendizagens e os saberes mais significativos para os três grupos-pesquisadores, o que interessava muito à própria escola comunitária que estava num processo de avaliação de seu trabalho educativo. Rapidamente a pesquisa se tornou uma pesquisa intercultural, por causa da freqüência da associação das imagens vistas pelos co-pesquisadores com temas culturalmente marcados no mundo afrobrasileiro baiano.

A técnica é explicitamente indutora de metáforas. Selecionando algumas metáforas particularmente vivas e problematizadoras da vida cognitiva das crianças, temos, no lugar Labirinto, as falas seguintes, comentários dos seus desenhos pelas crianças (Gauthier, 1999b, p. 317):

Apostando correndo sozinha, a menina muito alegre foi ajudada pelos bichos [em outros lugares muito perigosos, podendo comer a menina] a matar um ser humano (Esta menina é abusada, ela se chama Carla Perez, comenta M., a autora da imagem);

[...] uma princesa desmaiou de fome e sede, procurando uma saída, conforme uma estória lida pela autora da imagem, I., que gosta muito de estórias de princesas. Opostos a isso, os deveres chatos quando se repetem;

$\mathrm{Na}$ aula de arte misturamos as cores, como aconteceu no passeio que fizemos e que serviu de quadro para a prova de biologia (e chegou a pergunta: De que cor são os anjos?);

Existem saberes nos quais é melhor não entrar, por medo de não poder sair, como o saber das drogas, ou como quando, frente à criança curiosa, os adultos (pai ou professora) se contradizem, ou não dão explicações satisfatórias, ou praticam avaliações arbitrárias.

Cruzando essas metáforas com outras oriundas de outros lugares geomíticos, os facilitadores puderam propor para contra-análise, ou seja, avaliação pelas crianças e discussão problematizadora, uma forma de pensamento metafórico do grupo-pesquisador inteiro (o que Ricoeur chama de verdade metafóri$c a$ ). Esse pensamento é constituído de seres intermediários entre o afeto e o conceito, que chamamos na sociopoética de confetos. Por exemplo, a solidariedade cognitiva pode minimizar certos perigos. A arte possui também esse poder: no Arco-íris, ela assume uma parte de morte, ódio e mau-olhado. Sem a arte, a gente mataria, parecem afirmar as crianças. Aqui, arte e solidariedade cognitiva são confetos.

No método sociopoético, é solicitado aos co-pesquisadores pensarem com base nessa conclusão aberta. Essa reflexão pode gerar transformações pessoais ou institucionais, ou não. $\mathrm{O}$ grupo-pesquisador produziu seu próprio questionamento e os facilitadores não pretendem induzir respostas ou mudanças. Essas dependem do grupo hóspede da pesquisa e do desejo de cada ator co-pesquisador.

\section{Conclusão: \\ a questão da interpretação e da conceitualização}

Existe um importante trabalho dos filósofos, em duas direções: seja para darem vida às metáforas, ao ouvirem o que está subliminarmente cantando na linguagem e encantando-o, seja para criticarem o que a metáfora carrega de não analisado no conceito e apurálo desses elementos meio afetivos, intuitivos e confusos. Aliás, geralmente os filósofos trabalham nas duas direções, pois se trabalhassem somente na primeira eles seriam poetas, e se trabalhassem somente na segunda sem vida seria a sua língua filosófica, cortada da criatividade da linguagem cotidiana. 
Interpretar é um processo que acontece entre tirar a máscara da metáfora e respeitar seu segredo. Apesar de suas orientações filosóficas muito diferentes, tanto Deleuze e Guattari (1991) como Ricoeur (1975) insistem para que se diferencie o mundo do conceito filosófico do mundo do afeto e da metáfora: não se pode confundir o plano de imanência, onde nascem os problemas e seus afetos próprios, com o plano de consistência, onde insistem e interligam-se os conceitos, para Deleuze e Guattari; nem o mundo da metáfora, vida da língua que ignora a separação entre emoção e cognição, com o mundo do conceito, pensamento especulativo que possui seu próprio regime discursivo, para Ricoeur.

Como vemos, a sociopoética favorece a criação de confetos. Mas, como pesquisadores, precisamos igualmente de conceitos distanciados das cores, dos toques, dos cheiros, dos sons e dos gostos violentos e doces, maravilhosos e vergonhosos que constituem, para nós, o sentido da vida, metáfora gigantesca, sublime e terrível. Kant, no parágrafo 49 da sua terceira Crítica (1987, p. 144), expressa essa idéia com gênio, ao mostrar que a apresentação da Idéia pela imaginação obriga o pensamento conceitual a pensar mais: "Ao ampliar esteticamente o próprio conceito de maneira ilimitada, a imaginação torna-se criadora e coloca em movimento a faculdade das Idéias intelectuais (a razão)". Isso, acrescenta Kant, "[...] a fim de pensar, na oportunidade de uma representação [...] muito mais que aquilo que pode ser entendido nela e claramente concebido". E Ricoeur completa (1975, p. 383): “[...] toda interpretação visa a reinscrever o esboço semântico desenhado pela enunciação metafórica num horizonte de compreensão disponível e conceitualmente dominável".

Assim, assume a sociopoética o desafio da tradução - outra forma de transporte, diferente da metáfora - dos confetos em conceitos. Isso é o momento que Deleuze e Guattari chamam de desterritorialização, sendo o conceito caracterizado pelas suas potências de fugir de todo quadro de produção (sócio-histórico) dado e de entrar em combinações intensivas com outros conceitos. O conceito vai variar, intensificar, combinar, criando as condições dos problemas identificados (Deleuze \& Guattari, 1991, p. 26-28). Os conceitos são: "centros de vibrações, cada um em si e uns em relação aos outros".

Do lado de Ricoeur, o conceito vai entrar em diálogo com outras criações filosóficas, radicalmente distanciadas da experiência. Na língua de Deleuze e Guattari, um conceito vai ser experimentado, ${ }^{8}$ na língua de Ricoeur, interpretado. Nos dois casos, ele vai ganhar sua autonomia em relação a seu contexto de emergência.

A sociopoética pretende atender a essa exigência, pela análise do pensamento do grupo-pesquisador como se o grupo fosse um filósofo só, criador de conceitos. Aí o grupo-pesquisador precisa da ajuda do facilitador da pesquisa, que tranqüilamente, em casa, vai se perguntar: Como esse grupo estrutura o mundo que ele vai construindo através da pesquisa? Primeiro, quais as linhas de separação ou exclusão que ele traça, nas palavras usadas por ele para dizer sua experiência em relação ao tema orientador da pesquisa? (momento das análises classificatórias). Segundo, quais as ligações secretas que ele estabelece entre vários planos dessa experiência? (momento do estudo transversal). ${ }^{9}$

Esse trabalho é difícil, mas permite a elaboração de conceitos desterritorializados, que não são mais misturados com afetos, que o grupo vai, em seguida, discutir, criticar, avaliar e experimentar, conforme nossa concepção peirceana da conclusão hipotética.

8 "Um conceito exige [...] uma encruzilhada de problemas, onde ele se alia com outros conceitos co-existentes" (Deleuze \& Guattari, 1991, p. 24). E, na página 25: “O conceito de um pássaro não se encontra na sua espécie mas na composição de suas posturas, cores e cantos". E ainda, página 26: "O conceito diz o evento, não a essência ou a coisa”.

${ }^{9} \mathrm{O}$ processo de produção de metáforas vivas é particularmente solicitado, na sociopoética, no momento surreal, quando se pede aos co-pesquisadores para criarem novas imagens, oriundas dos encontros inesperados que aconteceram durante esses estudos classificatórios e transversais. 
Pode ser um conceito inovador da prática educacional, nunca pensado antes da pesquisa, ou mais humildemente, um conceito desterritorializado nas margens dessa prática, mas que pode trazer amplas mudanças na instituição, por causa de sua potência intensiva, ou de variação, ou de ligação, ou de contaminação. Um único conceito criado e exposto com alegria vale um doutorado inteiro, e não anula as intensidades vivenciadas com os atores da pesquisa. Pelo contrário, ele potencializa essas intensidades, ao voar como uma águia, ou um gavião, gritando seu ritornelo.

Darei somente um exemplo de tal conceito cocriado pelo grupo-pesquisador de crianças da Escola Comunitária Luiza Mahim em Salvador, em colaboração com os facilitadores da referida pesquisa financiada pelo $\mathrm{CNPq}$, que pesquisaram as estruturas implícitas do pensamento do grupo-pesquisador. ${ }^{10}$

É o conceito mesmo de aprendizagem, assim definido: é um momento na busca da sabedoria da vida, que acontece por um processo mais global de cuidar do outro, de sonhar com ele, em que a beleza, a sede de justiça e a solidariedade têm um papel determinante. Paz, proteção e firmeza, segurança e autolegitimação são buscadas na conquista dos saberes, apesar de as crianças desconfiarem das provas e das lógicas instituídas. Vivenciando processos de lento amadurecimento, elas buscam a ancestralidade e suas raízes, criando ludicamente e pela arte sua própria potência-no-saber, diferente da potência do outro, como seres aprendentes. Experimentam com paixão na busca do saber. Parasitando, até, outros saberes, as crianças não ignoram a empatia e a intuição como fontes de aprendizagem. Procurando o respeito mútuo, elas alteram-se e conseguem, às vezes, traduzir os saberes uns em outros, tentando iniciar sua entrada num espaço novo, o espaço do conhecimento, com regras próprias. Sua paixão está dirigida contra a fragmentação do saber e contra a exclusão, pelos saberes academicamente legítimos, da sabedoria da vida.

${ }^{10}$ Ver uma apresentação dessa pesquisa em Gauthier e Gauthier, 2001, p. 69-89.
Vemos aqui funcionar um conceito deleuziano, como centro de vibrações e variações, intensidade desterritorializada, que se combina em rede com outros conceitos. Obviamente, esse resultado não é independente do projeto político-pedagógico da escola, que os alunos conhecem. Sem dúvida, os comentários dos jovens co-pesquisadores sobre suas produções metafóricas não são totalmente livres dessa pressão institucional implícita.

Mas nunca podíamos prever, antes de realizarmos essa pesquisa, ou seja, esse tipo de pesquisa metaforizante, o grande peso das tradições africana e indígena no modo de aprender das crianças, cuidando do outro e procurando a sabedoria da vida. O que teríamos encontrado se tivéssemos somente utilizado técnicas de entrevista, sem termos tentado revelar parte do inconsciente institucional pela mediação da metaforização artística e sem termos analisado o pensamento do grupo-pesquisador como um todo, como se esse grupo-sujeito de crianças fosse um filósofo individual?

Provavelmente, resultados mais previsíveis, já presentes na consciência e na razão das pessoas.

JACQUES ZANIDÊ GAUTHIER, doutor em ciências da educação pela Universidade de Paris VIII, é professor de filosofia no Lycée de Muret, da Académie de Toulouse. Dentre suas publicações mais importantes, organizou GAUTHIER, Jacques, CABRAL, Ivone, SANTOS, Iraci, TAVARES, Cláudia M. Pesquisa em enfermagem: novas metodologias aplicadas (Rio de Janeiro: Guanabara-Koogan, 1998); GAUTHIER, Jacques, FLEURI, Reinaldo M., GRANDO, Beleni S. Uma pesquisa sociopoética: o índio, o negro e o branco no imaginário de pesquisadores da área de educação (Florianópolis: Núcleo de Publicações da UFSC, 2001); e publicou: GAUTHIER, Jacques e GAUTHIER, Leliana de Sousa. Le rapport au savoir comparé d'élèves, de parents et d'enseignants d'écoles de périphérie à Salvador de Bahia (Brésil): étude sociopoétique. In: CHARLOT, Bernard (org.). Les jeunes et le savoir: perspectives internationales (Paris: Anthropos/Economica, 2001). Pesquisa em desenvolvimento: A relação com o saber de alunos, professores e pais de uma escola comunitária francesa (La Prairie, Toulouse). Email: socpoet@wanadoo.fr 


\section{Referências bibliográficas}

BACHELARD, Gaston, (1957). La poétique de l'espace. Paris: PUF.

BAKHTIN, Mikhaïl, (1970). L'oeuvre de François Rabelais et la culture populaire au Moyen Age et sous la Renaissance. Paris: Gallimard. Tradução de Andrée Robel.

(1992). Marxismo e filosofia da linguagem. $6^{\mathrm{a}}$ ed.

São Paulo: Hucitec. Tradução de Michel Lahud e Yara Frateschi Vieira.

BARBIER, René, (1993). A escuta sensível em educação. Cadernos ANPEd, Belo Horizonte: Editora da UFMG, n. 5, p. 187-216.

, (1998). A pesquisa-ação. Brasília: UnB. Tradução de Lucie Didio.

BENVENISTE, Emile, (1966). Problèmes de linguistique générale. Paris: Gallimard.

BHABHA, Homi K., (1998). O local da cultura. Belo Horizonte: Editora da UFMG. Tradução de Myriam Ávila, Eliana Lourenço de Lima Reis, Gláucia Renate Gonçalves.

BOURDIEU, Pierre, (1982). Ce que parler veut dire: l'économie des échanges linguistiques. Paris: Fayard.

CASTRO JÚNIOR, Luís Vítor, BATISTA, Maria Geovanda, GAUTHIER, Jacques, (2003). Epistemologia no Auê e na Capoeira. $13^{\circ}$ Congresso Brasileiro de Ciência do Esporte. Anais.

CERTEAU, Michel de, (1980). L'invention du quotidien. 1 - Arts de faire. Paris: Gallimard.

COLETIVO DE AUTORES, (1999). Maniquando o saber escolar/comunitário: pesquisa sociopoética. Panorama Acadêmi$c o$, v. $3, \mathrm{n}^{\circ}$ 1. UNEB, Campus IV, Jacobina: UNEB.

DELEUZE, Gilles, GUATTARI, Félix, (1980). Mille plateaux. Paris: Minuit.

, (1991). Qu'est-ce que la philosophie? Paris: Minuit.

ECO, Umberto, (1991). Chifres, cascos, canelas. In: ECO, Umberto, SEBEOK, Thomas, S. (orgs.). O signo de três. São Paulo: Perspectiva. Tradução de Silvana Garcia, p. 228-229.

ECO, Umberto, SEBEOK, Thomas S. (orgs.), (1991). O signo de três. São Paulo: Perspectiva. Tradução de Silvana Garcia.

FOUCAULT, Michel, (1976). Histoire de la sexualité - v. I. La volonté de savoir. Paris: Gallimard.

FREGE, Gottlob, (1952). On sense and reference. In: Philosophical writings of Gottlob Frege. Oxford: Blackwell.
FREIRE, Paulo, (1987). Pedagogia do oprimido. $17^{\mathrm{a}}$ ed. Rio de Janeiro: Paz e Terra.

GARFINKEL, Harold, (1967). Studies in ethnomethodology. Prentice Hall. New Jersey: Englewood Cliffs.

GAUTHIER, Jacques, (1999a). Sociopoética: encontro entre arte, ciência e democracia na pesquisa em ciências humanas e sociais, enfermagem e educação. Rio de Janeiro: UFRJ / Editora EEAN.

, (1999b). A relação com o saber de alunos, pais e professores de escolas públicas e comunitárias na periferia de Salvador. Relatório de pesquisa, 441p. Brasília: CNPq (mimeo.).

GAUTHIER, Jacques, GAUTHIER, Leliana de Sousa, (2001). Le rapport au savoir comparé d'élèves, de parents et d'enseignants d'écoles de périphérie à Salvador de Bahia (Brésil): étude sociopoétique. In: CHARLOT, Bernard (org.). Les jeunes et le savoir: perspectives internationales. Paris: Anthropos/Economica, p. 69-89.

GRAMSCI, Antonio, (1977). Il risorgimento. Roma: Riuniti.

HESSE, Mary B., (1965). Logic, methodology and philosophy of science. Amsterdam: Bar-Hillel.

HESTER, Marcus B., (1967). The meaning of poetic metaphor. La Haye, Paris: Mouton.

KANT, Emmanuel, (1987). Critique de la faculté de juger. Paris: Vrin. Tradução de André Philonenko.

KRISTEVA, Julia, (1969). Semiotikè. Paris: Seuil.

LOURAU, René, (1970). L'analyse institutionnelle. Paris: Minuit. , (1988). Le journal de recherche: matériaux d'une théorie de l'implication. Paris: Méridiens Klincksieck.

McLAREN, Peter, (1997). Multiculturalismo crítico. São Paulo: Instituto Paulo Freire / Cortez. Tradução de Bebel Orofino Schaefer.

MORIN, E, (1986). La méthode 3. La connaissance de la connaissance. Paris: Seuil.

PEIRCE, Charles S., (1935-1966). Collected papers of Charles Sanders Peirce - 8 v. Editado por Charles Hartshorne, Paul Weiss, Arthur W. Burks. Cambridge, Mass: Havard University Press.

RICOEUR, Paul, (1975). La métaphore vive. Paris: Seuil.

RUSSELL, Bertrand, (1961). Introduction. In: WITTGENSTEIN, Ludwig. Tractatus logico-philosophicus. Paris: Gallimard. Tradução de Pierre Klossowski, p. 7-21.

SANTOS, Léa Austrelina F., (2001). Ética da coexistência: uma referência fundamental à proposição de uma educação 
pluricultural. Sementes: Caderno de Pesquisa, Salvador, UNEB, v. 2, no $3 / 4$, p. 37.

SARTRE, Jean-Paul, (1960). Critique de la raison dialectique. Paris: Gallimard.

SEBEOK, Thomas A., UMIKER-SEBEOK, Jean, (1991). Você conhece meu método: uma justaposição de Charles S. Peirce e Sherlock Holmes. In: ECO, Umberto, SEBEOK, Thomas, S., (orgs.). O signo de três. São Paulo: Perspectiva. Tradução de Silvana Garcia, p. 23.

SERRES, Michel, (1969). Hermes I. La communication. Paris: Minuit. , (1972). Hermes II. L'interférence. Paris: Minuit. , (1974). Hermes III. La traduction. Paris: Minuit. , (1977). Hermes IV. La distribution. Paris: Minuit. , (1980). Hermes V. Le passage du Nord-Ouest. Paris: Minuit.
, (1985). Les cinq sens: philosophie des corps mêlés 1. Paris: Grasset. , (1997). Nouvelles du monde. Paris: Flammarion.

SODRÉ, Muniz, (1999). Claros e escuros: identidade, povo e mídia no Brasil. Petrópolis: Vozes.

VARELA, Francisco, THOMPSON, Evan, ROSCH, Eleanor, (1993). L'inscription corporelle de l'esprit: sciences cognitives et expérience humaine. Paris: Seuil.

VYGOTSKI, Lev S., (1985). Pensée et langage. Paris: Editions Sociales. Tradução de Françoise Sève.

WITTGENSTEIN, Ludwig, (1961). Tractatus logico-philosophicus. Paris: Gallimard. Tradução de Pierre Klossowski.

Recebido em agosto de 2003 Aprovado em novembro de 2003 